\title{
ПОНИМАНИЕ ЧЕЛОВЕКА В ЭКЗИСТЕНЦИАЛЬНОЙ ФИЛОСОФИИ КАРЛА ЯСПЕРСА
}

\section{UNDERSTANDING OF MAN IN THE EXISTENTIAL PHILOSOPHY OF KARL JASPERS}

V. Skopa

Summary: The article presents an understanding of man in the existential philosophy of Karl Jaspers. It was revealed that the main subject of K. Jaspers'study is a person and history. The concept of the situation turns out to be key in the analysis of human existence. The ability for independent comprehension and free choice is the most important condition for a person's historicity. Freedom and identity are the true value of a person. Genuine self-determination of a person becomes possible only as a result of existential communication, which is understood as an internal, freely chosen connection between people, with the help of which they open up to each other as self-valuable and unique personalities.

Keywords: existence, Karl Jaspers, history, being, rationalism, existential communication.

\author{
Скопа Виталий Александрович \\ Д.и.н., Алтайский государственный педагогический \\ университет, г. Барнаул \\ sverhtitan@rambler.ru
}

Аннотация: В статье представлено понимание человека в экзистенциальной философии Карла Ясперса. Выявлено, что основным предметом изучения К. Ясперса является человек и история. Понятие ситуации оказывается ключевым при анализе человеческой экзистенции. Способность к самостоятельному осмыслению и вольному выбору является важнейшим условием историчности человека. Свобода и самобытность составляют истинную ценность человека. Подлинное самоопределение личности становится возможным лишь вследствие экзистенциальной коммуникации, под которой понимается внутренняя, свободно избранная связь между людьми, с помощью которой они открываются друг другу как самоценные и неповторимые личности.

Ключевые слова: экзистенция, Карл Ясперс, история, бытие, рационализм, экзистенциальная коммуникация.

а общая судьба многих людей, общность вместе пережитого. «Поэтому бессмысленно искать в истории свое предназначение, тем более рассматривать себя как ее вечного должника. Индивидуальная судьба, таким образом, должна быть постигнута не как необходимость темного, но в себе упорядоченного исторического процесса, а как ситуация, результаты которой определяются нашей людской свободой» [8, с. 294]. Таким образом, в своем стремлении уловить социально-исторические тенденции индивид удовлетворяет потребность не указателях, а в знании жизненных ситуаций, в рамках которых ему предстоит принимать собственные самостоятельные решения и совершать поступки, а не просто приспосабливаться.

Способность к самостоятельному осмыслению и вольному выбору, по Ясперсу, является важнейшим условием историчности человека. Такая способность имеет, по сути, непереходный характер, хотя и проявляет себя в различных исторических ситуациях в разной степени и формах [2, с. 12]. Она коренится в таких неотъемлемых атрибутах человеческой экзистенции, как свобода и неповторимость. Именно они побуждают человека не останавливаться в своем движении к тому, чего еще нет, но может и должно быть, и постоянно быть собой, быть верной себе, выбирать самого себя, то есть постоянно трансцендировать к себе как «самобытной самости» $[5$, с. 123]. 
Свобода и самобытность, ведущих к незаменимости составляют истинную ценность человека. Ведь именно свободная и самобытная личность является началом «высокого взлета» того или иного исторического периода. История - это постоянное и упорное движение вперед, что осуществляется, прежде всего, благодаря усилиям свободных и самобытных лиц - индивидуальностей, которые показывают пример и призывают других следовать за ними. Поэтому прошлое так часто и предстает перед нашим взором как ряд вершин, созданных действиями отдельных людей. Следовательно, «для того, чтобы быть историческим, индивид должен быть единичным, неповторимым, уникальным» [8, с. 249]. Показательно при этом, что Ясперс совсем не отрицает, как-то иногда утверждают его критики - марксисты, значение объективных обстоятельств, а также деятельности масс. А только видит в этой деятельности в лучшем случае стабилизационный, в худшем и наиболее распространенном - консервативно-деструктивный фактор общественных изменений. Дело в том, что «человеку свойственно считать свой образ жизни единственно правильным, чувствовать каждое существование, непохожее с его собственным, как укор, как посягательство на свои права, ненавидеть его. А это приводит к желанию навязать собственные представления другим» $[8, \mathrm{c}$. 176]. По факту мощные силы масс с их усредненными потребностями подавляют все то, что не соответствует их требованиям, все то, что, на их взгляд, не имеет смысла. Отсюда воинственный антииндивидуализм как характерная черта всей истории человечества. «Физическое уничтожение людей выдающихся, что задыхаются под давлением реальностей массы - явление, которое чаще всего встречается в истории», - утверждает Ясперс [8, с. 259]. Указанные особенности массового сознания - главная психологическая предпосылка для популизма. По мнению философа поскольку «массы сами по себе не обладают свойствами личности; они ничего не знают и ничего не хотят, они лишены смысла и служат орудием того, - в духе Нише утверждает Ясперс, - кто льстит их общим психологическим страстям» [8, с. 144]. Таким образом, не массы, а индивидуальность, свободно самоопределяется, выступает активным началом и стимулятором исторических изменений. Поэтому лучшие люди это те, что пытаются быть сами собой, в отличие от тех, кто убегает от себя в своем стремлении избавиться от страха и ответственности. И именно поэтому столь важным для нашего времени является вопрос, как в нынешней ситуации сохранить такое достижение, как индивидуальная неповторимость каждого человека, его высокое достоинство, свобода духа [3, с. 188].

Ясперс не стремится к противопоставлению индивида и общества. Однако в ситуации массового нивелирования и деперсонализации он акцентирует внимание на том, что действительно гуманистическое решение многих проблем человеческого существования возможно лишь при условии, что они станут глубоко личными, а не формально общими, что связь индивида с обществом будет осуществляться не по принуждению, а свободно, что позволит личности возможность выбора и внутреннего принятия этого выбора как своего собственного. Поэтому, действительно «человечное» - нравственное и гуманное существования общества, возможно только при таких условиях [5, с. 126]. И тем более не может идти речи о какой изоляции лица от общества, если принять во внимание ту огромную личную ответственность, которую, по Ясперсу, должен нести каждый человек не только за свои собственные поступки, но и всего, что происходит в мире.

У К. Ясперса личная свобода и личная ответственность неотделимы друг от друга, а также от свободы всего общества, поскольку лишь при условии свободного самоопределения индивида, считает мыслитель, возможно требование ответственности за его действия. С другой стороны, «там, где невозможны ответственность за судьбу целого и свободное участие в его управлении, там - все рабы» [8, с. 207]. Поэтому «быть самим собой», по Ясперсу, вовсе не означает замкнуться в себе и отгородиться от общества. «Человек зависит от себя как единичного, - пишет он, - в новом смысле: она должна сам помочь себе ...» [8, с. 377], то есть сам себя сделать, а не надеяться на какие-то высшие силы. И этот процесс самосотворения не имеет ничего общего с самоизоляцией. Недаром центральным понятием всей философии К. Ясперса является понятие коммуникации как универсальное условие человеческого существования [4, с. 251]. При этом важно отметить, что под коммуникацией понимается не просто общение, а процесс, с помощью которого человек, раскрывая себя в других, самоопределяется и становится самим собой, то есть реализует свою «самость».

В соответствии с логикой К. Ясперса - только тогда, когда коммуникация приводит к раскрытию глубинного ядра личности - экзистенции, основными характеристиками которой как раз и есть свобода и уникальность. То есть, подлинное самоопределение личности становится возможным лишь вследствие особой - экзистенциальной коммуникации, под которой понимается внутренняя, свободно избранная связь между людьми, с помощью которой они открываются друг другу как самоценные и неповторимые личности [7, с. 81].

Предварительным условием вхождения в экзистенциальную коммуникацию является одиночество индивида, которое вызывает появление страха, что выводит индивида из состояния легкомысленности и растворения в массе. Раскрытие себя другим и стремление понять другого, безусловно, порождают риск трагической ошибки. Но индивид должен идти на это, если он желает действительного самоопределения [6, с. 107]. Важным усло- 
вием экзистенциальной коммуникации являются личные переживания предельных ситуаций, которые раскрывают глаза на истинные ценности и смысл человеческого существования из-за встречи с трансцендентным.

Одной из главных причин введения понятия трансцендентного в систему Ясперса является стремление философа обосновать возможность индивидуальной свободы. Благодаря этому, личная свобода выводится из-под естественной и социальной необходимости и становится независимым источником человеческого самоопределения. Его свобода, хотя и является относительно безусловной к миру имманентного, тесно связана с миром трансцендентного как гарантом личной ответственности [9, с. 51]. В тех ситуациях, когда свобода все-таки превращается в нигилизм и анархию, что более всего характерно для массового сознания переходных эпох, усилиями тех же самобытных, действительно свободных и потому ответственных лиц достигнутые «вершины» трансформируются в усредненные, доступные массам формы, что ведет к определенной стабилизации общества.

Таким образом, именно наличие в обществе неординарных, независимых личностей, является важнейшим условием его динамизма. «Движущие силы безграничной динамики Запада вырастают из «исключений», - заявляет Ясперс, - которые прорывают здесь всеобщее. Запад отводит определенное место исключениям. Он допускает в ряде случаев новую жизнь и деятельность и потом иногда так же решительно уничтожает их. Природе человека удается здесь иногда достичь вершин, которые отнюдь не получают всеобщего признания, к которым, возможно, вряд ли кто-нибудь хочет» [10, с.87]. И если присущие современной эпохе явные и скрытые тенденции к господству масс и тоталитаризма получат верх, если исчезнет почва для появления неординарных, самобытных лиц, способных к свободному самоопределению, - то наступит такой конец, - предостерегает Ясперс, - который мы даже не можем себе представить.

\section{ЛИТЕРАТУРА}

1. Власова 0.А. Ясперс и Хайдеггер: по следам утраченных разговоров // Вопросы философии. 2015. №11. С. 65-73.

2. Гайденко П.П. Человек и история в экзистенциальной философии Карла Ясперса (Вступ. статья) // К. Ясперс. Смысл и назначение истории. М., 1994. С. 5-26.

3. Сидоренко И.Н. Карл Ясперс. М., 2008. 361 с.

4. Соловьев Э. Прошлое толкует нас. М., 1991. 432 с.

5. Хміль В.В. Умови історичності людини та людяності історії за Ясперсом // Антропологічні виміри філософських досліджень. 2017. Вип. 12. С. $121-127$.

6. Юнг К. 0 современных мифах. М., 1994. 252 с.

7. Ясперс К. Ницше и христианство. М., 1994. 114 с.

8. Ясперс К. Смысл и назначение истории. М., 1994. 527 с.

9. Ясперс К. Разум и экзистенция. М., 2013. 312 с.

○ Скопа Виталий Александрович (sverhtitan@rambler.ru). 